\title{
SOME THOUGHTS RELATIVE TO THE ETIOLOGY OF DEGENERATION.
}

By CHAS. E. WOOdRUfF, M. D., U. S. ARmy,

Fort Riley, Kansas.

A few years ago, when it was popular for every one to write about degeneration, and when it was the fashion to discover evidence of degeneration in every abnormality which a man possessed, it was generally supposed that such unstables would naturally flock to the army and that splendid opportunities must there exist for the study of the stigmata of this interesting condition. Such a study was at first to a large extent forced upon the writer as the result of a peculiar combination of circumstances, and has since been continued by him in his spare moments. At first the investigation was surrounded with peculiar diffculties, for nowhere, except in special journals, could one find a description of what a degenerate really was. The average ideas were so vague and so tinctured with phrenology and metaphysics as to be of no use to a beginner. The popularity of the Lombroso School of Criminal Anthropology gave rise to the impression that every criminal must be a degenerate. When it was discovered that some criminals-particularly criminals from passion and those whose youth had been passed in bad surroundings-were physically normal and that, on the other hand, degenerates were found among the most moral of men, it became evident that the actions of any given individual were not entirely the result of an abnormal development, but were in part due to his environment. When it was attempted to class every criminal among the degenerates, it followed that undue prominence was given to abnormalities not infrequently found in normal men. In like manner confusion followed from considering the insane as degenerates, whereas not seventy-five per cent of them belong to this class. It was extremely difficult, 
[Oct.

then, to determine with precision what were the stigmata of degeneration. The deeper one goes into the subject, the more and more does the study lead us into the science of anthropology, and becomes more and more foreign to a physician's ordinary lines of thought. Again, the further one investigates, the more is he convinced that variations from the average may be strictly normal in one man and an evidence of extremely unstable development in another. Thus degeneration is discovered to be a highly complex condition resulting from an endless succession of causes acting upon the ovum from the moment of conception, or upon the parents or their ancestors so as to modify the germ cells long before their union. Degeneration is a process so interwoven with evolution and development, that to understand it one is led into all sorts of by-paths of study in embryology and its branches of teratology, in heredity and the diseases connected with it, in anthropology-the origin and disappearance of races and the characters of the present ethnic types-in evolution and man's descent, and a host of side issues following from a comprehension of the laws of the origin of species. Thus it would be easy to find oneself engaged in what would appear. to be an almost hopelessly involved and interminable investigation. Unless one succeeds in getting a clear general idea of degeneration but investigates only one side, he is apt to make statements which some other writer will flatly contradict or which he himself will later retract. Lombroso himself has had to change his opinions so radically on certain topics that he now occupies a position opposite to that at first held by him.

Much of the contempt thrown upon this subject would have been avoided, had investigators possessed a simple knowledge of the laws of organic evolution, and a consequent ability to separate in their minds the normal from the abnormal. For instance, there is no normal or average individual in any species; variation is the rule, and it is by taking advantage of these minute normal variations better adapted to the environment than the average, that species are gradually changed by the survival of the fittest. On the other hand, variations cannot be marked because it has been established as the very foundation law of heredity that offspring must closely copy their parents, 
and wide variation would involve a loss of adjustment leading to the extinction of that line of individuals in the species. Thus there is no normal or average man; and it is difficult to conceive of a man each of whose characteristics is the exact average of that characteristic in all the individuals in his race. We all vary and no two men are alike. Yet such minute normal variations grade so imperceptibly into the marked abnormal differences due to unstable development that it is absolutely impossible to make a rigid classification. Every definition must be in general terms, and these will not apply to borderland cases any more accurately than in any other biological science.

We can, therefore, define a degenerate as an abnormal man whose variations or stigmata are developmental and due to an unstable nervous system. The variations from the average may also be due to diseases resulting from an unstable nervous system, such as rickets and the deformities of infantile paralyses. So long as we recognize that the essential defect of the degenerate depends upon the faulty composition of the substance of the nerve cell or its ancestor, the germ cell, although the character of the defect may be absolutely unknown, we are justified in using the unscientific term, nervous instability. We are perfectly aware of its indefiniteness, yet until the pathologist shall have taught us all about the composition of the nerve cell in health and disease, we can find no other term which will define a condition which, however, we know to exist.

It is also known that the neurotic condition may appear in every conceivable grade, from the normal to the extreme types encountered in the clinic, and that ill-defined borderland cases must exist. It is, therefore, evident that every grade of degeneration is met with and that it is not scientific to make two classes of men-the degenerate and the normal. The borderland types may be more or less degenerate, somewhat degenerate, slightly degenerate, or may be described by any other terms expressive of degree. A recognition of this fact would have saved the expression of many a bad opinion. Thus a slightly degenerate boy, according to his training and environment, may become a useful citizen or a scoundrel, and the study of such cases gives us no sure information as to the real effect of his abnormality. Such cases, indeed, may be so puzzling that 
two investigators may come to directly opposite opinions. The modern training of defectives and the abandoned children of degenerates is accomplishing such wonders as to upset many ideas held only a few years ago. In no other study will one be so astonished at the wide difference between the opinions he first holds and those he gradually forms.

Again, the stigmata of degeneration in marked cases are of so extreme a type that we cannot fail to distinguish them, but the minor stigmata are nothing more nor less than slight exaggerations of normal variations found in all men. These stigmata, being everywhere present, have such an uncertain value that their significance may be great or nothing. In saying that they are present in all men it is not meant that all men are tinctured with degeneration - a ridiculous conclusion at which we should arrive if we gave these stigmata a high diagnostic value. Such a statement would be no more true than the assertion that all men are more or less insane, because every man has normal variations from the average psychical characteristics of his race.

It is very unfortunate that biologists should have appropriated " reversed selection" properly called involution, or the retrogression of parts once useful but now useless, as exemplified by the vermiform appendix. This process is a matter of selection and manifests itself in the survival in greater numbers of those individuals in whom the useless parts are least developed by normal variation. It has positively nothing whatever in common with degeneration of family lines due to nervous instability. Involution is a wholesome process leading to survival; degeneration is an unwholesome process leading to extinction. Parasitism is a normal, wholesome involution, and not the degrading process certain religious writers like Drummond would lead us to believe.

What increases this unfortunate confusion of different processes and makes it doubly obscure is the fact that degeneration, by causing arrests of development, may produce anomalies identical with those resulting from involution. For instance, absence or defect of the wisdom teeth may be purely involutional in a normal man, because these teeth are disappearing from the race; yet in a degenerate their absence may be a real stigma indicating an abnormal arrest of development. The former may 
be a direct inheritance from normal parents, but the latter may be an abnormally wide variation from normal parents with large wisdom teeth. Such an identity of defects, which may be due to either one of two antagonistic processes, complicates this study almost hopelessly, but differentiation may be possible in accordance with the above law that normal variations do not depart widely from the parental form, while as a rule, the contrary holds for degenerate variations.

Another normal condition, which all writers ignore, is to be found in the wide diversity of normal variation resulting from civilization. According to the laws of evolution, man or his ancestor developed his brain at a time when his surroundings were very severe and only the most intelligent survived. Thus, each generation had more brain than its predecessor, and this progress may have occurred in glacial times. In no other way is it possible for the average intelligence of a race to increase. When the environment softened, and men had more intelligence than was needed merely for survival, the surplus brain power was naturally devoted to other ends, and civilization began with its division of labor. At first one man found that he could chip flints better than someone else, and by bartering these get more meat than he could obtain by hunting. This process has continued to such minute subdivision, that now a workman does but one little thing all his life, and often passes his whole existence in dense ignorance of all subjects outside of his speciality. Every savage had to have considerable intelligence to do all the necessary things in the adverse environment which must have existed in Northern Europe four thousand years ago. At present it is possible for a man to live well who has so little intelligence that he would have perished in a savage life. Hence, as an invariable rule in civilization the increase of the average brain weight by natural selection has stopped; and if we introduce civilization to a race undergoing such evolution in an adverse environment we soften that environment so as to preserve the less intelligent and thus check the further evolution of the brain. The longer a race has been kept in an adverse environment necessitating a brutal struggle for existence, the bigger are the bodies and the brains, as we see in going north in Europe until we meet a climate which is so adverse as to in- 
terfere with nutrition. Small-skulled civilized races, like the Peruvians, have without any reasonable doubt met with a mild environment very soon, perhaps many thousands of years ago, and their skull growth was checked at that time. Savage skulls in severe climates are much larger than the average civilized skull, and such races have invariably been able to advance to a civilization far beyond that of the races from whom they borrowed the first steps. This, to our certain knowledge, has been the history of Europe for the last two thousand years. Civilization results from brain; it has never produced an ounce of brain, and all the universities in the world will never balloon out our skulls by a single cubic inch.

Savages, therefore, all being compelled to do the same things, vary extremely little from one another, and their skulls show a wonderful uniformity. When we go back to prehistoric skulls in any one locality, they all seem to have been made from the same mould. Variations could not survive. The environment of civilization makes it possible for greater and greater variations to survive, so that the higher the civilization the more marked are the variations from the average. Thus it happens that variations, which among savages could only occur as a result of disease, are now so perfectly normal that their possessors leave healthy offspring to continue the line. Such normal variations, moreover, may be identically the same as others which result from degeneration, and the separation of them is extremely puzzling. To guide us, however, there remains the old law, that in the normal and stable man, developmental variations cannot be markedly different from similar variations in the parent. In unstable or degenerate development, the offspring is not controlled by normal checks and may wander into any channel and never resemble the parent closely except in rare cases and as a lucky chance. Much has been written about this transformation of heredity in the degenerate, for it is a very common observation that in such families there is a wide diversity of forms among near relations. As an example of the opposite nature, the writer knows a father, son and grandson, having anomalies of minor parts so marked as to be called stigmata by specialists; and yet the three are such laughable images of each other that anything else than normal stable development is 
almost impossible, it being highly improbable that unstable creatures should have thrice developed in the natural groove. In like manner there is ground for the belief that some of Lombroso's criminal types represent merely marked normal variations in individuals who are not degenerate but transmit their characteristics stably and accurately from generation to generation; and who, had they been properly educated during development, as is further explained below, might never have come into conflict with the law.

There has never yet been an unchallenged illustration of the transmission to the offspring of an acquired modification due to use, disuse or the general environment. Again, the work of Weismann in proving the impossibility of such transmission, unless it be of such a character as to interfere with the nutrition of the germ cells, has done much to call attention to the fact that nervous instability is not nearly so much a matter of inheritance, as it was once thought to be, but is rather a result of interference with nutrition, poisoning by toxins or alcohol, or of mechanical accidents to the ovum, and is probably to be found in normal families far more often than was once believed. This general condition of nervous exhaustion, nerve starvation, or alteration of the chemical composition of the nerve substance, cannot be called a variation in the sense in which Weismann uses the term. $\mathrm{He}$ is dealing with health, we with disease. Yet in the beginning the process must have been derived from normal parents and was not an inheritance but a real modification due to the environment-an acquired characteristic in the strict scientific sense. Again, there is, perhaps, ground for a suspicion that it is not transmitted at all, that degeneration is not hereditary, but that the ova always tend to revert to the normal if they are permitted to do so. Of course we know that environmental modifications may be so severe as to be fatal, a rule applying to men as well as to bacteria; and that modifications, though less severe, may nevertheless prevent the production of viable offspring, or may give rise to offspring not strong enough to have normal children. If the young children of degenerates, not too far from the average, could be properly nourished and raised and then kept healthy, sober and industrious, their offspring might be normal if similarly treated; that is, a real regeneration 
may occur. This is the rule with low forms of life, for even after bacteria have been "attenuated" or modified by an adverse environment, their descendants revert at once to the normal type as soon as the proper environment is restored by passage through a susceptible animal. Of course we do not mean by regeneration the restoration of an individual to the normal, for that would be as impossible as changing an imbecile into a genius. Regeneration and degeneration refer to the family lines and not to the individual.

The word regeneration has, by the way, been already appropriated by the biologists who have given a scientific meaning to it, having nothing in common with the term as employed by the anthropologists. The biologist means by regeneration the reproduction of lost parts, such as the growth of a new claw by a lobster after the old one has been lost by accident, the growth of a new eye by a snail or a new tail by a lizard under similar circumstances. In the lowest animals, like polyps or worms, the whole body may be regenerated from a part containing sufficient reproductive power, but the higher the animal the less becomes this power of regeneration, in man being limited to the repair of epithelial structures, severed nerves and like processes.

Unfortunately for degenerates, the rule is for them to do the very things which are the most harmful for themselves and their germ cells and their children. They progressively increase the adversity of the environment, and the condition of malnutrition, nerve-starvation, exhaustion or degeneration, or whatever we may call it, is progressively intensified by more modifications due to the environment, until non-viable offspring or sterility ends the line-nature's way of purifying the race.

The momentous importance of Weismann's theory as applied to the care and raising of the children of degenerates needs no emphasis. The practical results of such nurture are superb. Children of the slums taken early, fed and raised in honest families, as a rule, become normal citizens in spite of terribly degenerate parentage. We read of the results with delighted astonishment. This theory may also do away with that fatalism which condemns degenerates and their offspring as hopelessly incorrigible, and which gives rise to the various absurd proposals for preventing their reproduction. Efforts at regenera- 
tion will take the place of nature's brutal methods of ruthless destruction of the least fit, as it is the rule for civilization to preserve and make useful that which was formerly destroyed by nature with reckless prodigality. Unfortunately the adverse environment of an abnormal intrauterine life may be so disastrous that no subsequent care can repair the damage already done, so that degenerates will be encountered so long as man exists.

Physicians are brought into such frequent contact with families in which there seems to be a direct handing down of an acquired vicious physique or tendency to disease, that it is almost a matter of religious faith to believe in the transmission of acquired characteristics. We even believed in the transmission of bacteria and that children were born consumptive. The first blow to this idea was the discovery that the transmission of disease is very rare, and that the consumptive, for instance, only inherits a tendency to infection, which represents only a natural variation and not an acquired modification. In some savage tribes, every normal man is extremely susceptible, while in other races, like the Jews, the susceptible individuals have been so thoroughly killed off that there are none left. We have been blinded by the fact that the natural variation is made effective by unsanitary living, and that even in the worst families the great majority will recover if, early after infection, they are placed in a propet environment. One physician ${ }^{1}$ even suggests the probability that through some species of antitoxin, the children of tuberculous parents acquire an actual immunity during development and that they are far better able than the average man to resist infection provided only that they are brought up under good surroundings. Similarly it has been affirmed that syphilis is never inherited, but that it is always a new infection acquired perhaps months after the beginning of the existence of the foetus as a new being. These rules are now being applied to all apparently hereditary diseases-they are acquirements which might have been prevented in a proper environment.

It is almost impossible to believe that degeneration is not hereditary, for evidence to the very opposite seems to be before

${ }^{1}$ Glick, Charlotte Med. Jour., Nov. I899. 
our eyes daily. It may be of assistance in clearing up the muddle to remember that degeneration is possibly always due to vicious causes which injure the ovum before or after fertilization, and divert it during development from the natural groove into which it is naturally directed by the hereditary impulses accumulated by natural selection from millions of previous generations. If it were hereditary the children should resemble the parents, whereas they usually differ.

That they do tend, when permitted, to seek the normal or revert to the form from which their parents have been modified, is evident from the results of improving the environment of the slum children of degenerate parents. These unfortunates seem to acquire degenerate modifications from the moment of their conception straight on throughout their whole development. If degeneration were hereditary there would be an end to hope of regeneration. Yet genealogical studies show that family lines are constantly varying from and to the average. Some lines end in the most abnormal classes-the highest and the lowestand these are constantly undergoing change. Aristocratic and degraded families generally last only a few generations before becoming extinct or reverting to the average-the great middle normal class-unless they are kept alive by intermarriage with new normal blood. The upper and lower crust has to be constantly recruited with aberrant types from the middle class-the real people.

It is not at all unlikely that if the fertilized ovum of degenerates could be nourished in a normal womb, it would prove that it did not inherit degeneration, and would develop normally, that is, if it were not already too much damaged by poisons or malnutrition. As such an improved environment is impossible to attain, we must expect degenerates to be born in degenerate families as a result of modification. If one means by inheritance such intrauterine modifications, then of course degeneration is just as much an inheritance as color or stature. Accurately speaking, however, when the germ and sperm cells have united the new creature has received its whole inheritance and thereafter it can only be modified from the form into which it would naturally develop, if it could be promptly cared for. Weismann lays special stress upon this fact, and we must limit the word heredity as the biologists do. 
Practically, we find that degenerates have degenerate children and it is a matter of the most extreme importance to the community to know whether this fatal pseudo-inheritance is going to make the child develop into the image of its degraded parents, or whether, if taken in hand early, it cannot be nourished so as to develop into a useful citizen. Philanthropists are doing this very thing, though of course we know that it is impossible to repair the damage already sustained by the time of birth.

Again, a certain amount of neurosis, if we may so express it, is undoubtedly a normal variation following upon the preservation of extreme variations by civilization, and we must expect transmission in such cases which we have perhaps unjustly considered abnormal. In man, as in dogs and horses, the nervous system may normally vary in stability from the most phlegmatic to those " high-strung," "high-pitched " nervous " types which require such careful management. The latter represent borderland types reaching over into the abnormal neurotics. We must keep in mind the biological law, that a part developed in one species to a greater degree than in allied species, tends to be highly variable. The human brain follows this law, and its variations, both organic and functional, though very great, are strictly normal.

We have long known that criminals are such from necessity and not from choice, and that after they are fully matured, reformation is just as impossible as the regeneration of an imbecile. The belief naturally followed that criminals were born so, but the strict application of Weismann's theories would disprove this. Certainly the good results following the careful training of the youngest criminals tends to show that crime is far more the result of an adverse environment than we once believed-an acquired modification not transmissible, and not a hereditary variation. Of course the more degenerate a child, the more easily does it react to the evil influences of a bad environment and the more hopeless will be the efforts to raise it to a normal manhood. Indeed, the whole matter of the nontransmission of acquired characters or modifications due to environment is removing the foundations of our pet theories. Dr. G. Archdall Re1d, has called renewed attention to this point in the Lancet in the discussions of the temperance reform. Many 
writers positively deny the transmission of the acquired drink craving; and Sullivan, in the Journal of Inebriety, shows that the malign effects of alcohol consist in the poisoning of the foetus, and mother, for in drunken women, the successive children are more and more damaged until non-viable ones are born-the reverse of what occurs in syphilitic infections.

It is unfortunately true that all the facts of degeneration can be logically explained, whether one believes or does not believe with the Neo-Darwinians, that acquired characters are absolutely non-transmissible. This theory emphasizes the important fact of the absence of degeneration in the average man, and holds that species are carried on or modified by those individuals which vary but a trifle from the average and not by those which vary the most. The latter, like the highest and the lowest men, either die out or tend to revert to the normal or average. Ernst Haeckel, in his studies of the evolution of new species, lays special stress on the biological law that aberrant types generally perish and that the survivors are those which hug closely to the main evolutionary stem-a law just as applicable to aberrant individual variations as to aberrant species or orders. 